test $^{3}$ and in which there was no significant shift as a result of therapy. Like Frost-Larsen et $\mathrm{al}^{\mathbf{4}}$ we did not include details and results of all the investigations performed in our report, which had been abbreviated at the Editor's request. Tear break-up time was estimated; Rose-Bengal staining, labial gland biopsy, and sialography were also performed. The unreliability of these in assessing lacrimal and salivary gland involvement have been discussed previously. ${ }^{5} 6$

The mean unstimulated salivary flow rate in our Sjögren's patients of $0.17 \mathrm{ml} / \mathrm{min}$ or $2.55 \mathrm{ml} / 15 \mathrm{~min}$ (fig 1 ) is below our normal range of $0 \cdot 27-1.88 \mathrm{ml} / \mathrm{min}$ and below the normal mean values previously established by other workers using the same method of collection. $^{78}$ However, too much emphasis should not be placed on mixed salivary flow measurements compared with stimulated parotid flow rates, which are considered to be more reliable in assessing the degree of xerostomia. $^{6}$

We note that Dr Manthorpe and his colleagues have still not cited any pharmacological mechanism whereby bromhexine could increase secretion from pure serous glands such as the lacrimal and parotid glands.

\section{M TAPPER-JONES} M J ALDRED D M WALKER A E DOLBY

L BECK R HOPKINS

Departments of Oral Medicine and Oral Pathology, Periodontology, Ophthalmology, and Oral Surgery,
Welsh National School of Medicine, University Hospital of Wales,
Cardiff CF4 4XY

Rheumatic Diseases Unit, Northern General Hospital, Edinburgh EH5 2DQ

${ }^{1}$ Bloch KJ, Buchanan WW, Wohl MJ, Bunim JJ. Medicine 1965;44:187-231. Medicine 1965;44:187-231.
${ }^{2}$ Mackie IA, Seal DV. Br F Ophthalmol 1976;60:70-4.
3 van Bijsterveld OP. Arch Ophthalmol 1969;82:10-4. Frost-Larsen K, Isager H, Manthorpe R. Br Med $\mathcal{F}$ 1978; i:1579-8

s Mackie IA, Seal DV. Br Med f 1978;ii:638.

Chisholm DM, Mason DK. Br Dent $\mathcal{F}$ 1973;135 393-9.

Zaus EA, Fosdick LS. F Dent Res 1934;14:1-13.

err AC. The physiological regulation of salivary secretions in man: a study of the response of human
salivary glands to reflex stimulation. Oxford: salivary glands to
Pergamon Press, 1961.

\section{McIlroy-a suggestion}

SIR,-McIlroy, ${ }^{1}$ that most famous example of Munchausen's syndrome, continues his peregrinations. He was admitted to this psychiatric unit on 15 September complaining of depression. The next morning he "collapsed," simulating a cardiac infarct, and was transferred to Jervis Street General Hospital. He was subsequently returned to St Brendan's after his cardiac status was deemed satisfactory. While arrangements were being made for his readmission to the ward he departed. Over the next two days we traced him to five other Dublin hospitals, but since 18 September he has disappeared again.

The literature on McIlroy, while anecdotal and colourful, tells us little about the man himself. We are therefore writing to you with the suggestion that McIlroy, wherever he next appears, should be taken into hospital (compulsorily if necessary) for the specific purpose of a full in-depth psychiatric evaluation. Moreover, the possible side effects of the prodigious amount of investigations he has had, such as the radiation effects of hundreds of $x$-rays, clearly need monitoring. In short, McIlroy in his own right now merits serious psychological and somatic study. For our part we in St Brendan's are willing to accept him for such studies should he reappear again in Eire. We suggest that a unit in the UK do likewise.

A J MCGENNIS St Brendan's Hospital, M J CORRY Dublin 7

${ }^{1}$ Pallis CA, Bamji AN. Br Med $\mathcal{F}$ 1979;i:973-4.

\section{Diuretics are dangerous with lithium}

SIR,-Dr R J Kerry and others (2 August, p 371) have re-emphasised the established fact that thiazide diuretics cause reduced lithium clearance leading to increased serum lithium concentration and sometimes lithium toxicity. It is not at all clear, however, that this interaction occurs with classes of diuretics other than the thiazides. ${ }^{1}$ Although evidence is limited, available data suggest that diuretics of the osmotic, carbonic anhydrase inhibitor, and xanthine types actually increase lithium excretion. Long-term use of potassium-sparing diuretics (spironolactone, triamterene, amiloride) may lead to lithium retention, although this observation is based on a single study. When frusemide ( $40 \mathrm{mg}$ daily) was given to five normal volunteers, there was no change in serum lithium level over a two-week period, suggesting that the interaction of loop diuretics with lithium may be quite different from the thiazides. ${ }^{2}$

Although the danger of giving lithium with diuretic drugs has been well substantiated only with the thiazides, I do agree that careful clinical and laboratory monitoring is indicated when lithium and any diuretic are combined in a medically ill patient.

Finally, it should be noted that thiazide diuretics have proved to be quite effective in the treatment of lithium-induced nephrogenic diabetes insipidus. In such situations it is generally necessary to lower the lithium dose to compensate for drug-induced lithium retention. ${ }^{3}$

J W JEFFERSON

Lithium Information Center,

University of Wisconsin Department of

Psychiatry,

Clinical Science Center

Madison, Wisconsin 53792, USA

1 Jefferson JW, Greist JH. In: Davis JM, Greenblatt $\mathrm{D}$, eds. Psychopharmacology update: new and neglected areas. New York: Grune and Stratton, 1980:

81-104. JW, Kalin NH. FAMA 1979;241:1134-6. 225-7.

\section{Treatment of sciatica}

SIR,-I am writing to raise a few points about your reply in "Any Questions ?" (30 August, p 606) about the treatment of classical sciatica. This question is clearly rather too difficult to answer in the short space available and perhaps the attempt should not have been made, but since it was may I make the following comments?

(1) Myelography has largely been replaced by radiculography for defining root lesions. (2) I doubt if the consensus is that a definite disc protrusion is an indication for surgery. (3) It is untrue that a negative myelogram excludes a reasonable chance of improving sciatica by surgery unless a comment is made about age. A young patient with definite sciatic and clinical findings of root compression may have bony compression in the absence of disc protrusion. (4) Analgesics alone should rarely be used anyway; an anti-inflammatory drug gives consistently better results in patients with early acute sciatica and may give better results in the older patient with degenerative arthritis. Indeed, pathology, investigation, prognosis, and management are really very different at different ages. (5) A fenestration procedure would probably be considered preferable to laminectomy. (6) Finally, I have never seen "classical sciatica" improved by specific psychiatric treatment.

Michael SNaIth

\section{Department of Rheumatology and \\ Rehabilitation, \\ University College Hospital,}

* * (1) Radiculography is used in relatively few centres for defining root lesions and myelography appears to be the most widely used technique in Britain. (2) In a patient with a definite disc protrusion failure to respond to conservative treatment is in most people's opinion the prime indication for surgery. (3) A negative myelogram was not said to exclude a reasonable chance of improving sciatica by surgery; it simply reduces the chance of cure. (4) Although anti-inflammatory agents may give better results analgesics are more widely used. (5) Fenestration is admittedly a more accurate term for the standard operation but laminectomy remains the more commonly used term. (6) There are patients with apparent classical sciatica, usually of the chronic variety, in whom secondary depression is an aggravating factor requiring treatment.-

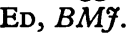

\section{Private versus public health care systems}

SIR,-In a review in this journal (14 June, p 1428) Lord Taylor of Harlow has some very uncomplimentary things to say about my book The Health Care Business. ${ }^{1}$ While there is nothing I can do about the fact that he does not agree with my conclusions, I would like to correct some gross inaccuracies in his representation of the book's contents.

(1) Nowhere in the book do I state or imply that the NHS is "very inefficient" (nor that "Sweden has the most efficient health care in the world"). I attribute the low cost of health services in the UK, relative to Canada and the US, to a number of factors, such as an efficient system of GP services ( $p$ 138) and substitution of less expensive paramedical personnel (such as home nurses) for physician manpower (p 131). I also claim, however, that one reason for the relatively low cost in the UK is the fact that some categories of patients who would be given specialist or hospital' treatment (or both) in North America are given simple and less expensive treatment (or no treatment at all) in the UK. The aspects of the UK health care system which Lord Taylor cites as evidence of my ignorance ("We would seldom admit a patient with an upper respiratory infection"; "Thanks to our good GP service and excellent home nurses ... we treat a great deal of terminal illness at home"; "In Britain, the GP is a powerful barrier to any unnecessary admission") seem to me to support these explanations, not to contradict them. As I conclude in the book, the North American health care systems might have some lessons to learn from the NHS in these areas, but not from the "long waiting lists for cold surgery," which I do take to represent an undesirable feature of the UK health care system. 
(2) Lord Taylor paints a lurid picture indeed of the situation he thinks would result under the sort of system I advocate: "Inside, one found 15000 patients being looked after by two or three doctors. . . . Examinations were non-existent and so-called 'spot-diagnosis' was the rule." I see no reason whatsoever why my proposals that the State's responsibility should be limited to guaran teeing "universal access to a minimum level of adequate care" would produce this kind of result. It obviously would correspond to a standard of care falling below what is considered "minimally adequate" in today's society. As I state in the book ( $p$ 152), what level of care would be "minimally adequate" is a value judgment and would require a political decision; but it is certain that it would be higher than the standards prevailing in some northern towns in England in the 1930s and 1940s.

(3) I am castigated by Lord Taylor for advocating "the best available care only for those who can and will pay for it." Yet he himself goes on to say that "the right to buy a second opinion, from the consultant of one's choice, seems to me an essential of good medicine," and states that all NHS doctors should have the right to some private practice. It seems to me that, at least under the present British system, this "essential of good medicine" is indeed available only to those who can and will pay for it.

(4) One of my proposals is that individuals should themselves be required to arrange, and pay the full cost for, the health insurance they buy. I argue that this can be accomplished without making any individual or family financially worse off, by "selective changes in the progressive income tax and in the welfare system" (p 177). Lord Taylor, in discussing this, complains that "what happens if [certain families or individuals] pay no income tax is not explained." The explanation is that such families or individuals get a transfer from the government. It seems to me that one does not have to read my book particularly carefully to realise this implication.

(5) Trying to discuss uses of the market mechanism in the health services field presents difficulties a little akin to those that faced a young man attempting to discuss the subject of sex with a nineteenth century virgin. In the latter case, at the first mention of the word the lady would utter a piercing scream and rush to seek the protection of an elderly aunt. In the former mention of the word "market" provokes the cry of "Friedman!" (to whom there is not a single reference in my book), and a lecture on the deplorable conditions in health care in northern England during the 1930s and 1940s.

If that is the level at which the issues are to be debated, I would be forced to agree with Lord Taylor that the exercise is a waste of time. But it does appear to me that if one is going to come up with ideas for resolving some of the difficulties facing the health care systems either in the UK or in North America a more serious examination of alternatives involving partial use of the market mechanism may be both interesting and helpful.

London, Ontario, Canada

Åke BlomQvist

'Blomqvist A. The health care business. Vancouver: Fraser Institute, 1979.

\section{Community medicine: a second chance?}

SIR,-Your timely leading article "Community medicine: a second chance" (27 September, p 826), the report on recruitment to community medicine ( $p$ 886), and the impending second Health Service reorganisation create the opportunity to comment on the future of this specialty at this crucial time.

I believe that the most important function of community medicine is that of planning, which in addition to resource aspects (money, manpower, buildings) should include a clinical and patient- or problem-orientated content. This should comprise assessment of need, determination of priorities, and some aspects of clinical audit and evaluation. As I see it, this will entail close collaboration between clinicians and community physicians so that community medicine can become what it should be-clinical medicine in a population. I believe that this is essential to the survival and establishment of community medicine as a specialty. I believe medical education-both undergraduate and postgraduate-to be very important in developing community medicine along these lines.

Two types of community physicians are needed: epidemiologists and managers (that is, for co-ordination, implementation, etc). There is a need for at least one of each in every district and there is scope for more than one epidemiologist at regional level, where there should be close contact with academic departments at medical schools. For epidemiological work there will be a need for adequate support staff at both regional and district level-clerical, secretarial, and statistical. From my experience of teaching secondyear preclinical students at a London teaching hospital, epidemiological studies can be carried out by both undergraduates and postgraduate community medicine trainees unde the supervision of experienced researchers.

JOHN LEE

Department of Community Medicine and Health, Kingston and Richmond Area Health Authority,

***A leading article on clinical epidemiology appears at p 1163.-ED, BMF.

\section{Audit of the work and performance of a surgical firm}

SIR,-I was interested to read the article by $\mathrm{Mr} \mathrm{M} \mathrm{H} \mathrm{Gough} \mathrm{and} \mathrm{others} \mathrm{about} \mathrm{the} \mathrm{annual}$ assessment of the work and performance of a surgical firm (4 October, p 913).

One problem in this type of audit is the variable endpoint for inclusion of postoperative complications, such as wound infection. This is particularly true following appendicectomy, where early discharge is the rule, hospital follow-up by no means universal, and wound infection more common than is generally realised.

I would agree that the wound infection rate for the Oxford series appears "agreeably low" at eight out of 126 appendicectomy cases $(6 \%)$. The paper states that all morbidity that occurred in hospital was recorded, but that patients after uncomplicated appendicectomy were not routinely followed up. I suspect, therefore, that the wound infection rate quoted refers only to those infections noted before discharge from hospital, which can be misleading.

In a current study in Brighton, 38 consecutive patients who underwent appendicectomy for acute non-perforated appendicitis, with peroperative antimicrobial cover, have so far been followed up for one month postoperatively. As in the Oxford series, most of these patients went home around the fourth postoperative day, and only two wound infections were apparent before discharge from hospital $(5 \%)$. However, a further six patients developed wound sepsis (for the most part of a minor nature) between leaving hospital and the time of their follow-up visit four weeks later, the true wound infection rate being a much less acceptable $21 \%$.

Royal Sussex County Hospital,
Brighton BN2 5BE

J D MORRISON

\section{Pay of AMOs and RMOs}

SIR,-Your report of the CCHMS meeting (18 October, $\mathrm{p}$ 1083) gave details of the views of consultants on whether area and regional medical officers in receipt of merit awards should continue to have them abated by the amount of their salary supplement. You further report a decision on the matter by the CCHMS, but fail to indicate that the decision was simply whether to support the Central Committee for Community Medicine in its negotiations on this matter.

Nevertheless, the whole matter demonstrates clearly how one craft committee can block the negotiations of another. This feature of medical politics is well recognised by the DHSS officers, for on almost every occasion that the CCCM negotiators raise some new matter with the DHSS in the Joint Negotiating Body the rapid response is that we must get agreement first from the CCHMS or the JCC or both. One wonders whether the same technique is used against the other craft committees or only against community medicine.

Eaglestone Health Centre,
Eaglestone, Milton Keynes MK6 5AZ

D P B MILES

\section{Juniors' evidence to Review Body}

SIR,-Having received appropriate assurances from the Doctors' and Dentists' Review Body, the Hospital Junior Staff Committee, which represents all junior hospital doctors, has decided to submit evidence to it for the 1981-2 annual pay review. The HJSC has discussed its approach to the forthcoming review and I have also talked with chairmen and secretaries of regional committees as well as attending several regional meetings to ask for opinions.

I have no doubt that junior doctors are becoming increasingly frustrated at being regarded as sources of cheap labour by the NHS. Their concern about UMT payments, long hours of work, and deteriorating working conditions is being aggravated because they face uncertainty over their future careers. As the main priority in our evidence I have been asked to press for a large increase in UMT payments to reflect the responsibility and major contributions made by junior doctors to health care. Thus employing authorities would have to rethink their attitudes to the nature and extent of junior doctors' work as well as their attitude to manpower. Even where consultant expansion is supported locally by the profession, this often does not come about because of financial restrictions. Instead, authorities either seek to employ more junior staff or to increase the work load of existing staff. This trend seems to be borne out by the recent increase in the number of hours worked by junior doctors.

I have already written to regional hospital junior staff committees but I am particularly anxious to get to as wide an audience of junior staff as possible and would welcome any comments from them as it is vitally important that our evidence is truly representative of junior hospital doctors. I would be grateful, 